\title{
Zapoviédnik, de Serguei Dovlátov: traduzindo a cultura e o riso
}

\section{Zapovednik, by Sergei Dovlatov: translating culture and laugh}

\author{
Yulia Mikaelyan* \\ Le rire est le propre de l'homme. \\ François Rabelais
}

\begin{abstract}
Resumo: A especificidade da tradução do humor consiste em que a recepção do cômico depende não tanto da forma linguística na qual é expresso, mas, principalmente, da contextualização do receptor (ou seja, do leitor do texto) na cultura correspondente. Isto exige outras estratégias da transferência do significado para conservar o efeito cômico. Neste trabalho, pretendemos analisar as estratégiasda tradução da novela Zapoviédnik, de S. Dovlátov, para as línguas inglesa, francesa e para o português do Brasil, propondo a nossa variante da tradução. 0 escritor russo trabalhou com prosa humorística, e uma das características de sua comicidade é a forte ligação com a cultura russo-soviética. Na tradução, esses momentos podem perder uma parte de sua expressividade e, principalmente, de sua comicidade. Com certeza, no caso da tradução de sua obra, esse se configura como o maior desafio para o tradutor.
\end{abstract}

Palavras-chave: Serguei Dovlátov; tradução de prosa humorística; transferência cultural; cultura russa; literatura russa.

Abstract: Translating humor is always a complicated task, because the reception of the comic depends not so much on the linguistic form in which it is expressed, but mainly on the context of the receiver (i. e., the reader) in the corresponding culture.

" Doutoranda do programa de Literatura e Cultura Russa do Departamento de Letras Orientais da FFLCH/USP. Email: ymikaelyan@usp.br 
MikaELYAN, Y. - Zapoviédnik, de Serguei Dovlátov: traduzindo a cultura e o riso

This requires the transfer of other strategies meant to preserve the comic effect. In this paper, we analyze the strategies of translating the novel Zapovednik, by the Russian writer Sergei Dovlatov, into French, English and Brazilian Portuguese, proposing our translation variant. Dovlatov always worked with humorous prose, and one of the features of his writing is a strong connection with the Russian-Soviet culture. In translation, these peculiarities may lose a part of their expressiveness, especially their humor. Indeed, this presents the biggest challenge for the translator of Dovlatov's works.

Keywords: Sergei Dovlatov; humoristic prose translation; cultural transference; Russian culture: Russian literature.

\section{Introdução: Serguei Dovlátov, um escritor russo na América}

O nome do escritor russo Serguei DovláTov (1941-1990) ainda é muito pouco conhecido entre os leitores brasileiros. Até agora, no Brasil, foi publicado apenas um conto seu, "Na rua e em casa”, na Nova antologia do conto russo, em 2011 (título em russo, "Na úlitse i doma”; tradução de Mário Ramos e Yulia Mikaelyan), além de um fragmento de seu romance A mala (em russo, Tchemodán; tradução de Marina Darmaros), no caderno Ilustríssima da Folha de São Paulo (edição do dia 06.11.2011). Apesar do pequeno número de traduções em português, tanto na Rússia quanto no Ocidente, Dovlátov é considerado por críticos literários, como Igor Sukhikh, Aleksandr Guénis ou Jekaterina Young, entre outros, um dos maiores representantes da contística russa da segunda metade do séc. XX e um dos principais escritores russos na emigração (Young 2009: 48), no contexto da assim chamada Terceira onda de emigração russa (o escritor emigrou para os EUA em 1978, na onda de emigração que levou da União Soviética para o exterior um grande número de escritores, artistas e intelectuais russos que não concordavam com o regime estabelecido no país, os assim chamados dissidentes). Cabe mencionar que a literatura de emigração russa é estudada como um gênero à parte por críticos e teóricos 
MikaELYAN, Y. - Zapoviédnik, de Serguei Dovlátov: traduzindo a cultura e o riso

russos e ocidentais, a partir de suas características bastante específicas, como uma literatura produzida em língua russa, mas fora de seu contexto social.

Ainda em vida, Dovlátov ganhou reconhecimento não apenas entre o público da colônia russa no exterior, mas também entre os leitores estrangeiros: durante doze anos de vida na emigração, praticamente toda sua obra foi traduzida para o inglês, e seus principais romances e novelas também foram traduzidos para outros idiomas, como francês, alemão, espanhol, italiano, turco, entre outros. Nos Estados Unidos, as traduções de seus contos foram publicadas em revistas americanas de referência, como New Yorker e Partisan Review. A obra de Dovlátov chegou à Rússia logo após a sua morte, no começo dos anos 1990, depois da queda da Cortina de Ferro, e desde então ele continua sendo um dos escritores da segunda metade do século XX mais lidos e mais queridos pelos leitores russos (SUKHIKH 2006: 218).

Dovlátov trabalhou principalmente com prosa humorística e uma das especificidades de sua comicidade é sua forte ligação com a realidade e a cultura russo-soviética. Ou seja, seu humor, na maior parte dos casos, é culturalmente marcado: o efeito cômico na obra de Dovlátov, em muitas situações, é elaborado com base em fatos da cultura, com a pressuposição de que o leitor possui conhecimento prévio sobre esses fatos.

Sua novela Zapoviédnik (1983) é considerada por muitos críticos uma das melhores obras do autor (ibid.: 129). Nela, o escritor recria a própria experiência de trabalho como guia no complexo histórico MikháilovskoeTrigórskoe, na região de Montes Púchkin, que antes era propriedade do poeta Aleksandr Púchkin (1799-1837) e até hoje funciona como parque-museu em sua memória.

O tema determina o caráter "literário" da novela: no texto abundam referências ao patrimônio literário russo, tanto no nível da narrativa quanto no nível da poética da linguagem e da construção das personagens. 0 escritor faz várias alusões, muitas vezes em forma humorística, tanto à vida e à obra de Púchkin quanto a outros clássicos de literatura russa, como Dostoiévski, Gógol, lessiênin, entre outros. Tais referências ao passado e ao presente da literatura 
Mikaelyan, Y. - Zapoviédnik, de Serguei Dovlátov: traduzindo a cultura e o riso

e da cultura russa tornam bastante complexa a estrutura do texto, gerando várias camadas de significados. 0 próprio Dovlátov, nas cartas a seu editor e amigo Igor Efímov, dizia que considerava Zapoviédnik dificilmente traduzível para outras línguas devido a tal conexão muito forte do texto original tanto com a língua quanto com a cultura russa (Dovlátov, EFímov 2001: 407). No entanto, a novela foi traduzida para vários idiomas e a sua tradução para o português do Brasil está atualmente em processo de preparação.

No presente artigo, pretendo analisar as possíveis estratégias da transferência do humor e das marcas culturais na tradução desta novela para o português do Brasil, além das línguas inglesa e francesa. Para isso, será usado o texto da novela Zapoviédnik em russo e suas traduções para o inglês (sob o título The Pushkin Hills), para o francês (Le domaine Pouchkine) e para o português (título provisório, Patrimônio cultural).

\section{Tradução de humor e transferência das marcas culturais: suas especificidades e metodologia}

No campo teórico, os estudos do humor têm caráter interdisciplinar, em estreita relação tanto com a linguística, quanto com a psicologia e sociologia, dentre outras disciplinas. Tal interdisciplinaridade deve-se ao fato de que o humor está relacionado com muitos aspectos da vida e até da fisiologia humana: como aponta Jeroen Vandaele, o humor tem ligações com partes primitivas do cérebro humano que são associadas à socialização, às emoções compartilhadas e à redução do perigo ou da hostilidade (VANDAELE 2010: 148). Seu valor social e

\footnotetext{
${ }^{1}$ A tradução da novela para o português do Brasil forma parte integrante da tese de doutorado da autora deste artigo. - Y. M.
} 
MIKAELYAN, Y. - Zapoviédnik, de Serguei Dovlátov: traduzindo a cultura e o riso

importância para as relações dentro da sociedade e da cultura de uma dada nação são assinalados por muitos pesquisadores de todas as citadas áreas.

Por exemplo, como menciona Arlete Cavaliere em seu estudo sobre a comicidade e a paródia no teatro russo, já na primeira metade do século $X X$ estudiosos russos como Bakhtin ${ }^{2}$, Likhatchov ${ }^{3}$ e Pántchenko ${ }^{4}$ abordavam a questão do humor e do riso no âmbito da tradição popular e da concepção do riso como:

um dos elementos essenciais para uma compreensão não apenas da natureza do homem em si mesmo, mas também da relação íntima entre o riso e os fatos de uma dada cultura como um todo, particularmente os fatos da linguagem, da literatura e da arte em geral (CAVALIERE 2009: 12).

A estreita relação do humor com a cultura e com a sociedade determina seu caráter implícito: o humor baseia-se num conhecimento implícito que possuem os portadores da cultura na qual ele é produzido, ou seja, depende de esquemas culturais implícitos.

Claro, existe um tipo de piada "inter" ou "binacional", na terminologia de Patrick Zabalbeascoa (em seu trabalho Humor and translation - an interdiscipline, o pesquisador propõe uma tipologia de piadas para a tradução, joke types for translation), para a qual os portadores de diferentes culturas possuem o mesmo conhecimento, valores e gostos que são necessários para compreender e apreciar essa piada da mesma maneira (ZABALBEASCOA 2005: 189). No caso, a transferência do humor na tradução acontece sem a necessidade de fazer algum tipo de adaptação. Mas, na maioria dos casos, a compreensão do humor, da piada, acaba sendo restringida pela visão de mundo, conhecimentos e hábitos da cultura na qual foi produzido.

\footnotetext{
${ }^{2}$ Mikhaíl Bakhtin (1895-1975) foi filósofo e teórico da cultura europeia e as artes, famoso por pesquisas sobre filosofia da linguagem e cultura.

${ }^{3}$ Dmítri Likhatchov (1906-1999) foi filólogo e teórico das artes, autor de vários estudos sobre a literatura e cultura russa.

${ }^{4}$ Aleksandr Pántchenko (1937-2002) foi filólogo e especialista em literatura e cultura russa.
} 
Mikaelyan, Y. - Zapoviédnik, de Serguei Dovlátov: traduzindo a cultura e o riso

Tal caráter implícito, conotativo do humor leva alguns pesquisadores à opinião de sua absoluta ou relativa intraduzibilidade, normalmente relacionados com suas características linguísticas e culturais (VANDAELE 2010: 149). Existem duas tradições na abordagem da tradução do humor: a prescritiva e a descritiva. A tradição prescritiva valoriza a tradução fiel ao texto original. Um dos seus adeptos, Jürgen von Stackelberg, caracteriza assim a postura prescritivista: "The question is $\langle. .>$ should the translator be allowed to make us laugh at his own ideas rather than at those of the author? We don't think SO." ${ }^{5}$ (apud VANDAELE 2010: 151) Tal opinião exerce uma pressão considerável no tradutor e leva a conclusões bastante pessimistas, ou seja, aceita a intraduzibilidade do humor.

Já na abordagem descritiva consideram-se as relações entre culturas, grupos, sistemas e tradutores, e, no caso de dificuldades no processo de tradução, procuram-se soluções que digam algo sobre o contato entre estas culturas, grupos e agentes. Assim, a comparação descritiva entre o texto de partida e o texto de chegada não vê o humor como uma categoria homogênea, mas estuda suas características cognitivas, emocionais, sociais e interpessoais.

$\mathrm{Na}$ tradução do humor, uma das especificidades cruciais consiste em que a recepção do cômico depende não tanto da forma linguística na qual é expresso, mas, principalmente, da contextualização do sujeito receptor (ou seja, do (eitor do texto) na cultura correspondente. Por isso, até uma ótima tradução no aspecto da língua pode não levar a uma recepção adequada do cômico, o que se expressará na diferença das reações do leitor do original e do leitor da tradução. Em outras palavras, é sempre o leitor que determina a piada ser engraçada ou não, rindo dela. Portanto, a não compreensão da piada traduzida, a perda de sua expressividade, leva à falha na comunicação e, consequentemente, na tradução.

\footnotetext{
5 "A questão é <...> se o tradutor tem a autorização de fazer-nos rirmos de suas próprias ideias em vez das ideias do autror? Não achamos que seja assim." - tradução da autora deste artigo, Y. M.
} 
MIKAELYAN, Y. - Zapoviédnik, de Serguei Dovlátov: traduzindo a cultura e o riso

A inclusão do receptor na tradução e a necessidade de considerar também as peculiaridades de caráter extralinguístico levam-nos à possibilidade de estudar a tradução do humor dentro da abordagem funcional-cultural dos Estudos da Tradução, que tem sua origem em meados da década de 1970, na escola alemã Skopostheorie. No caso da tradução do humor, trata-se da transferência do cômico não somente para outra língua, mas também para outra cultura, ou seja, de uma transferência cultural, na qual a cultura é concebida como

um fenômeno abrangente, que abarca todas as manifestações de um povo num ponto específico de um eixo espaço-tempo, estabelece uma relação de condicionantes recíprocas entre linguagem e cultura e inclui os elementos constitutivos da comunicação numa dada situação: emissor, receptor, meio, entre outros (AZENHA 2010: 39).

A abordagem funcionalista permite-nos analisar a tradução de um texto partindo da sua função. Segundo a visão funcionalista, expressa no ensaio de Katharina Reiss Type, kind and individuality of text: decision making in translation, um dos objetivos centrais da tradução interlingual é a produção de um texto funcionalmente equivalente ao original (ReIss 2000: 160). Portanto, na tradução do humor, em função do texto humorístico, o objetivo central do tradutor seria conservar a comicidade expressa no texto original.

Outro conceito dos Estudos Culturais da Tradução, que usamos neste trabalho, é o conceito da marca cultural. O termo será compreendido no sentido mais abrangente: serão denominados de marcas culturais não apenas os fatos referentes à realidade extralinguística própria de uma cultura, mas também "relações que ativam esquemas cognitivos e permitem identificar diferentes ângulos" (AZENHA 2006: 29) a partir dos quais o portador de determinada cultura enxerga e descreve o mundo. Portanto, na análise da novela Zapoviédnik, trataremos como marcas culturais não somente os fenômenos extralinguísticos, próprios da realidade e da cultura russas (como objetos, bebidas, costumes, entre outros), que não têm paralelos em outras 
culturas, mas todos os tipos de manifestação que reflitam as especificidades da visão de mundo do portador da cultura russa no nível da linguagem.

\section{Tradução de Zapoviédnik: diferentes} estratégias da transferência do humor e das marcas culturais

Como foi mencionado na introdução, o texto da novela Zapoviédnik contem várias camadas de informação implícita, referentes à cultura e à literatura russo-soviéticas, que o leitor russo reconhece facilmente, mas que, na maioria dos casos, podem não dizer muito para um leitor estrangeiro.

Um dos leitmotiv ${ }^{6}$ da novela é a presença do poeta Aleksandr Púchkin, cuja imagem aparece em várias formas e situações ao longo da narrativa. No parque-museu, as imagens do poeta e as alusões a seu aspecto visual sempre aparecem num tom irônico. A figura de Aleksandr Púchkin foi muito venerada pela ideologia oficial soviética: desde os anos 1920 começou a construção do mito sobre o poeta, pois o novo governo precisava de um símbolo da cultura e do país que fosse reconhecido pela maioria da população e que, ao mesmo tempo, representasse a história da Rússia e pudesse transmitir essa nova ideologia soviética (obviamente, a sua biografia fora modificada em prol da nova ideologia, eliminando todos os fatos e opiniões de Púchkin que não coincidiam com as ideias comunistas). 0 mito foi consolidado nos anos 1970, quando em toda cidade soviética havia uma rua, teatro, museu ou biblioteca (ou tudo ao mesmo tempo) que levava o nome do poeta ${ }^{7}$. Seus versos eram

\footnotetext{
${ }^{6}$ A palavra traduz-se do alemão como "motivo condutor". Na teoria literária, compreende-se por leitmotiv tema ou motivo nuclear persistente numa obra.

${ }^{7}$ A pesquisadora russa Marina Zaguidúllina apresenta o panorama de desenvolvimento do mito puchkiniano na Rússia e na União Soviética em seu livro Púchkinski mif v kontsé XX vieka ("O mito puchkiniano no final do século XX") (ZAGUIDÚLLINA 2001).
} 
MIKAELYAN, Y. - Zapoviédnik, de Serguei Dovlátov: traduzindo a cultura e o riso

decorados na escola e cada cidadão podia reconhecer o retrato de Púchkin: de cabelo encaracolado e de suiças, normalmente usando uma cartola. Para Dovlátov, o parque-museu, onde a figura do "Púchkin soviético" é idolatrada, representa o centro, o templo deste falso mito: referências a Púchkin, suas imagens e citações aparecem em todos os lugares, nem sempre apropriados. Por exemplo, o retrato do poeta aparece até embaixo da placa "Perigo: inflamável" e os garçons do restaurante vizinho ao museu usam também enormes suiças:

\begin{tabular}{|c|c|c|}
\hline russo & inglês & francês \\
\hline \multirow[t]{3}{*}{$\begin{array}{l}\text { Я сел у двери. Через } \\
\text { минуту } \\
\text { официант с громвился } \\
\text { войлочными } \\
\text { бакенбардами } \\
\text { 2003: 176). }\end{array}$} & $\begin{array}{l}\text { I sat by the door. A waiter } \\
\text { with tremendous felted } \\
\text { sideburns materialized a } \\
\text { minute later (DovLÁTov } \\
\text { 2013: 5). }\end{array}$ & $\begin{array}{l}\text { Je m'assieds près de la } \\
\text { porte. Une minute plus } \\
\text { tard, le serveur fait son } \\
\text { apparition, le visage } \\
\text { encadré par d'énormes } \\
\text { favoris de feutre } \\
\text { (DovLÁTov 2004: } 22 \text { ). }\end{array}$ \\
\hline & português & \\
\hline & $\begin{array}{l}\text { Sentei-me ao lado da } \\
\text { porta. Em um minuto } \\
\text { apareceu o garçom, com } \\
\text { enormes suiças de feltro. }\end{array}$ & \\
\hline
\end{tabular}

Embora a alusão a Púchkin seja evidente para o leitor russo (como foi dito acima, qualquer aluno de escola primária russa sabe que Púchkin tinha suiças), com certeza, apenas os leitores estrangeiros que possuam conhecimentos na área de literatura russa perceberão a ironia do autor. Esse tipo de alusão, de pequenos "traços", está espalhado ao longo do texto da novela. Nenhuma das duas traduções (para o inglês e para o francês) possui algum tipo de comentário ou nota a tal respeito. Para tornar a ironia visível na tradução, poderia ser usado o recurso de nota de rodapé, mas, na nossa opinião, isso carregaria muito o texto e assim eliminaria a leveza humorística que a novela possui em russo.

Além da figura de Aleksandr Púchkin, na novela abundam outras referências à história e à literatura russa e soviética, com as quais Dovlátov brinca. Um dos exemplos do humor tipicamente dovlatoviano é a conversa do 
protagonista principal, Boris Alikhánov, com a moça que trabalha no museu e se chama Aurora.

\begin{tabular}{|c|c|c|}
\hline russo & inglês & francês \\
\hline $\begin{array}{l}\text { - Давайте познакомимся. } \\
\text { - Аврора, - сказала она, } \\
\text { протягивая липкую руку. } \\
\text { - А я, - говорю, - танкер } \\
\text { Дербент (DoVLÁTov 2003: } \\
\text { 177). }\end{array}$ & $\begin{array}{l}\text { "Let's get acquainted." } \\
\text { "Aurora," she said, } \\
\text { extending a sticky hand. } \\
\text { "And I am," I said, } \\
\text { "Borealis." (DovLÁTOV } \\
\text { 2013: 6) }\end{array}$ & $\begin{array}{l}\text { - Faisons connaissance. } \\
\text { Elle me tend sa paume } \\
\text { poisseuse. } \\
\text { - Je m'appelle Aurore. } \\
\text { - Et moi Cuirassé } \\
\text { Potemkine (DovLÁTov } \\
\text { 2004: } 23 \text { ). }\end{array}$ \\
\hline & \begin{tabular}{l}
\multicolumn{2}{c}{ português } \\
- Vamos nos conhecer. \\
- Aurora, disse ela, \\
estendendo a mão \\
pegajosa. \\
- E eu sou o navio-tanque \\
Derbent ${ }^{8}$.
\end{tabular} & \\
\hline
\end{tabular}

Se no Brasil Aurora é um nome bastante comum, na União Soviética daquela época a primeira associação que surgia era o cruzador "Aurora", um dos símbolos da Revolução de outubro de 1917. Por isso o narrador faz a brincadeira com a associação que gera o nome da moça, apresentando-se como tánker Derbent ("navio-tanque Derbent”), no texto em russo.

Nas traduções em francês e em inglês, os tradutores fizeram adaptações para conservar o efeito cômico. Em francês, "navio-tanque Derbent" foi trocado por “encouraçado Potiómkin” (cuirassé Potemkine), nome de outro navio militar, muito mais conhecido, para fazer assim mais clara a referência à Revolução.

Já em inglês o tradutor decidiu afastar-se do tema da Revolução e propôs uma solução construindo a piada com base na expressão aurora borealis, “aurora boreal”. A brincadeira produziu o efeito cômico necessário, pois o nome do protagonista é Boris, portanto, sua resposta, em inglês, ao mesmo tempo faz alusão ao seu nome e também gera associações com o fenômeno

\footnotetext{
${ }^{8}$ Alusão à novela Tánker Derbent (1938), do escritor soviético lúri Krymov, considerada uma das obras clássicas do realismo socialista soviético.
} 
MIKAELYAN, Y. - Zapoviédnik, de Serguei Dovlátov: traduzindo a cultura e o riso

natural, a aurora boreal. Com certeza, tal adaptação permitiu conservar a comicidade do fragmento e sua expressividade na tradução.

Assim, nas duas traduções, foi usada a estratégia de domesticação, na terminologia de Lawrence Venuti. Os termos, propostos por Venuti, tomam sua origem no texto Sobre os diferentes métodos de traduzir, de Friedrich Schleiermacher. Nele, o filósofo teoriza sobre o antagonismo entre as duas únicas maneiras de traduzir: "Ou o tradutor deixa o escritor o mais tranquilo possível e faz com que o leitor vá ao seu encontro, ou deixa o leitor o mais tranquilo possível e faz com o que o escritor vá ao seu encontro" (apud BERMAN 2007: 10). Antoine Berman caracteriza o segundo método, ou seja, o método de domesticação, como etnocêntrico, já o primeiro, o de estrangeirização, ao contrário, "cultiva a língua materna pela incidência de uma outra língua e de um outro mundo" (ibid.: 10). Fazendo adaptações para acionar os conhecimentos dos leitores, os tradutores "domesticam" assim a tradução. Com certeza, no aspecto funcionalista, tais soluções permitiram transmitir na tradução o efeito humorístico presente no texto original.

No entanto, na tradução em português, optamos por manter a tradução "navio-tanque Derbent" e colocar uma nota de rodapé, pois Navio-tanque Derbent (em russo, Tánker Derbent) é nome da novela de lúri Krymov, uma das obras clássicas do realismo socialista soviético, à qual Dovlátov faz referência. Como foi dito antes, em Zapoviédnik, o contexto literário é muito importante, e a alusão ao clássico do realismo socialista (que, aliás, será percebida em russo apenas pelos leitores com um nível de cultura bastante elevado) é importante para o campo semiótico da literatura russa e soviética que o escritor constrói na novela. Embora, no caso, se perca a expressividade da piada, na tradução será mantido o fundo literário, alusão ao tema de literatura, tão importante no caso da presente obra.

Outro exemplo de humor é aquele que recorre ao estereótipo do alcoolismo na União Soviética, com as falas da personagem de Mikhal Iványtch, alcóolatra que aluga um quarto para Alikhánov na aldeia, ao lado do complexo histórico. Sua visão de mundo gira em torno do álcool, o que se reflete em sua 
Mikaelyan, Y. - Zapoviédnik, de Serguei Dovlátov: traduzindo a cultura e o riso

linguagem. Praticamente nenhuma de suas falas deixa de mencionar uma bebida alcoólica ou alguma situação de embriaguez: ele chega a medir o preço de aluguel por garrafas de bebida, além de outros exemplos. A sua visão de mundo se expressa plenamente na característica que ele dá aos vizinhos que teve.

\begin{tabular}{|c|c|c|}
\hline russo & inglês & francês \\
\hline $\begin{array}{l}\text { Прошлый год евреи } \\
\text { жили. Худого не скажу, } \\
\text { люди культурные... Ни } \\
\text { тебе политуры, ни } \\
\text { одеколона... А только } \\
\text { белое, красное и пиво... } \\
\text { (DovLÁTOV 2003: 195) }\end{array}$ & $\begin{array}{l}\text { Jews had it last year. I got } \\
\text { no complaints, the people } \\
\text { had class... No furniture } \\
\text { polish, no cologne... Just } \\
\text { red, white and beer... } \\
\text { (DovLÁTov 2013: } 26 \text { ) }\end{array}$ & $\begin{array}{l}\text { L'an dernier, c'étaient des } \\
\text { Juifs qui l'occupaient. Je } \\
\text { ne peux pas en dire du } \\
\text { mal, des gens bien } \\
\text { élevés... Ils ne bouvaient } \\
\text { jamais de vernis à l'alcool } \\
\text { ni d'eau de Cologne... } \\
\text { Seulement du vin blanc, } \\
\text { du vin rouge e de la } \\
\text { bière... (DovLÁTov 2004: } \\
\text { 46) }\end{array}$ \\
\hline & \begin{tabular}{l}
\multicolumn{3}{c}{ português } \\
No ano passado moraram \\
aqui judeus. Não posso \\
dizer nada ruim, gente \\
decente... Nada de álcool \\
de limpeza ou água de \\
colônia... Só branco, tinto \\
e cerveja...
\end{tabular} & \\
\hline
\end{tabular}

Analisaremos as marcas culturais presentes no fragmento.

Beber perfume ou outros líquidos que contenham álcool, na falta de bebida alcoólica, não é apenas hábito dos bêbados russos, e Mikhal Iványtch, no texto original, bebe politura, um tipo de verniz que contém em torno de $20 \%$ de álcool. Na época, politura usava-se na União Soviética como uma substituição barata de bebida alcoólica. Na França, existe um tipo de líquido parecido, vernis à I'alcool, portanto, o tradutor não precisou fazer adaptações para realizar a transferência cultural e procurar um referente paralelo na cultura de chegada.

Já na cultura brasileira e americana, tal referente não tem um equivalente exato. Para conservar a expressividade do texto original, optamos por colocar "álcool de limpeza", um paralelo que existe no Brasil, para 
MiKaELYAN, Y. - Zapoviédnik, de Serguei Dovlátov: traduzindo a cultura e o riso

contextualizar assim o leitor. 0 tradutor para o inglês também optou pela estratégia de domesticação, ao colocar furniture polish.

Outra marca cultural presente no fragmento é o reflexo da visão de mundo do alcóolatra soviético, para quem "gente decente" são pessoas que não bebem nenhuma mistura líquida que contenha álcool, mas apenas bebidas alcoólicas propriamente ditas; no caso, vinho e cerveja. No texto em russo, a informação de que o herói refere-se ao consumo de bebida alcoólica está implícita, pois Mikhal Iványtch não usa nem o verbo "beber", nem o substantivo para denominar o vinho, apenas suas características: "branco" e "tinto". Tal omissão atribui certa expressividade ao texto, demonstrando a familiaridade do personagem com o tema da bebida. Na tradução para o inglês foi conservada a referida omissão, já o tradutor para o francês acrescentou as palavras boire ("Ils ne bouvaient jamais...") e vin, empregando, assim, o recurso de explicitação. Em nossa opinião, essa tradução explicativa foi desnecessária, pois tornou explícita a informação que fora intencionalmente deixada implícita pelo autor. Como aponta Berman, o recurso de explicitação pode levar a duas tendências negativas: à clarificação ("explicitação visa a tornar "claro" o que não é e não quer ser no original" (BERMAN 2007: 51)) e ao alongamento (embora, segundo Berman, o alongamento seja "uma tendência inerente ao traduzir enquanto tal" (ibid.: 52)).

$\mathrm{Na}$ tradução para o português, optamos por manter a omissão das palavras "beber" e "vinho", para conservar, assim, a evidente familiaridade do herói de Mikhal Iványtch com o tema da bebida alcoólica e do alcoolismo.

No último fragmento, que analisaremos a seguir, o escritor faz referência a outro fato da cultura que é a "falta de homens" no perfil demográfico da sociedade russa. A preponderância da população feminina no país sempre foi objeto de piadas, e Dovlátov faz ironia com o fenômeno na conversa telefônica que uma das turistas tem com sua amiga. 
Mikaelyan, Y. - Zapoviédnik, de Serguei Dovlátov: traduzindo a cultura e o riso

\begin{tabular}{|c|c|c|}
\hline russo & inglês & francês \\
\hline 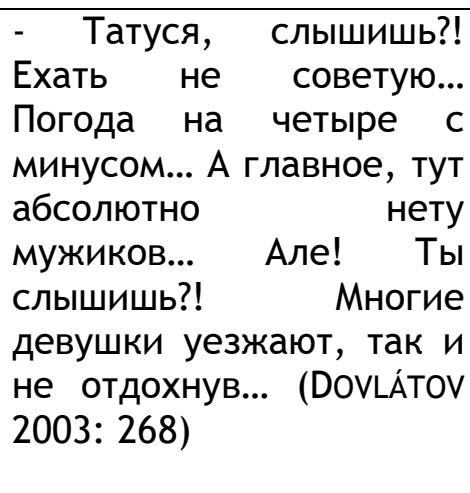 & $\begin{array}{l}\text { "Tata, do you hear? I } \\
\text { wouldn't advise you to } \\
\text { come... The weather here } \\
\text { is B-minus... But most } \\
\text { importantly, there are } \\
\text { absolutely no guys here... } \\
\text { Hello, do you hear me? } \\
\text { Lots of girls leave here } \\
\text { without ar... feeling } \\
\text { refreshed..." (DovLÁTov } \\
\text { 2013: 103) }\end{array}$ & $\begin{array}{l}\text { - Tatoussia, tu m'entends? } \\
\text { Je te déconseille de venir. } \\
\text { Le temps n'est pas idéal... } \\
\text { Et surtout, il n'y a pas un } \\
\text { seul mec... Allô, tu } \\
\text { m'entends? Beaucoup de } \\
\text { filles sont obligées de } \\
\text { rentrer sans s'être } \\
\text { reposées... (DovLÁTov } \\
\text { 2004: 137) }\end{array}$ \\
\hline & $\begin{array}{l}\text { português } \\
\text { - Tatússia, está me } \\
\text { ouvindo?! Não aconselho a } \\
\text { vir... O tempo não está lá } \\
\text { aquela coisa... E o mais } \\
\text { importante, aqui não tem } \\
\text { homem nenhum... Alô! Está } \\
\text { me ouvindo?! Tem muitas } \\
\text { meninas indo embora sem } \\
\text { nem ter descansado... }\end{array}$ & \\
\hline
\end{tabular}

Por causa desse viés demográfico (nos anos 1970, ainda eram sentidas as consequências da Segunda Guerra Mundial, que levou as vidas de mais de 26 milhões de pessoas na União Soviética; outro problema que contribuía para tal disparidade era o alcoolismo, tão comum entre a população masculina do país): para uma mulher solteira de meia idade era bastante difícil encontrar marido, e uma das possibilidades de conhecer pessoas eram as viagens turísticas. Por isso é tão grande a decepção da personagem que não encontra homens em Montes Púchkin.

Essa preocupação da mulher com "não poder descansar" por causa da falta de homens não é tão evidente para nativos de outros países que não enfrentem problema demográfico semelhante. Infelizmente, parece-nos que a piada perdeu uma parte da expressividade que tinha no texto original, por tal diferença entre culturas. Tentamos reforçar o efeito cômico, colocando na frase uma ênfase ("sem nem ter descansado"), ausente no texto original. 
MiKaELYAN, Y. - Zapoviédnik, de Serguei Dovlátov: traduzindo a cultura e o riso

\section{Conclusões}

Os exemplos analisados acima demonstram como Dovlátov, na construção do texto humorístico, aciona o tempo todo o conhecimento prévio do leitor, fazendo piadas contextuais. É um procedimento muito comum na sua poética que, com certeza, gera certas dificuldades para o tradutor, pois quando a comicidade é baseada na linguagem, o tradutor consegue achar um paralelo na outra língua que tenha uma expressividade semelhante. Porém, no caso da cultura, pelas diferenças nas visões de mundo, diferentes conhecimentos implícitos e, em alguns casos, ausência de referentes, resulta mais difícil realizar a transferência do humor, conservando o mesmo grau de expressividade.

Infelizmente, na tradução (e isso provam as três traduções analisadas aqui), uma parte da expressividade e da comicidade de seu texto se perde justamente pelas diferenças na visão de mundo entre os portadores de diferentes culturas e pela falta do conhecimento contextual para o leitor estrangeiro. No entanto, os textos analisados mostram que é possível realizar a transferência cultural, ao menos parcialmente, e transmitir o humor para outra língua e também para outra cultura, fazendo as adaptações necessárias.

Como demonstraram o cotejo e a análise das traduções para o inglês e para o francês, o recurso mais comum empregado pelos tradutores foi o recurso de domesticação, que permitia "fazer o escritor ir até o leitor", nas palavras de Schleiermacher, ou seja, adaptar a piada para a visão de mundo do leitor e conservar, assim, a expressividade do texto, embora, em muitos casos, seu conteúdo significativo seja diferente do conteúdo no texto original.

A análise das traduções também demonstrou que, no caso da tradução de um texto muito culturalmente marcado, como são os textos de Dovlátov, pode haver dois extremos: ou o tradutor tentar adaptar a tradução ao máximo

à cultura estrangeira e, então, perder a ligação com a cultura original e a intenção do autor, ou manter-se na tradução ao pé da letra, perdendo assim 
em muitos casos a expressividade e o charme da obra. Assim, por exemplo, usando demais o recurso da explicitação, ou seja, oferecendo a informação que está implícita no texto original, ou empregando demais o recurso de nota de rodapé, podemos poluir o texto e não deixar o leitor fruir a obra.

Com certeza, a diferença entre culturas é o ponto mais complexo desse tipo de tradução. 0 trabalho importante do tradutor, no caso, é não cair em nenhum dos extremos e manter-se no ponto de tensão entre as línguas e as culturas. Parece-nos que a tarefa é possível e, como prova disso, serve o fato do êxito das traduções da obra de Dovlátov até entre o público estrangeiro, não familiar com a cultura russa e soviética.

\section{Referências bibliográficas}

AZENHA JR, J. Linguística textual e tradução: redefinindo o conceito de "marca cultural”. In: TradTerm, № 12. São Paulo: Humanitas, 2006, pp. 13-32.

- Transferência cultural em tradução: contextualização, desdobramentos, desafios. In: TradTerm, № 16. São Paulo: Humanitas, 2010, pp. 37-66.

Berman, A. A tradução e a letra, ou, 0 al bergue do longínquo. Rio de Janeiro: 7Letras/PGET, 2007. Trad. de Marie-Helène Catherine Torres, Mauri Furlan, Andreia Guerrini.

CAVAliere, A. Comicidade e riso: do princípio aos fins. In: Teatro russo: percurso para um estudo da paródia e do grotesco. São Paulo: Humanitas, 2009: 9-32.

Dovlátov, S. Le domaine Pouchkine. Monaco: Éditions du Rocher, 2004. Traduit du russe par Christine Zeytounian-Beloüs.

. Pushkin Hills. London: Alma Classics, 2013. Translated by

Katherine Dovlatov.

. Zapoviédnik. São Petersburgo: Ázbuka, 2003.

DovLátov, S.; EFímov, I. Epistoliárnyi roman. Moscou: Zakhárov, 2001. 
Mikaelyan, Y. - Zapoviédnik, de Serguei Dovlátov: traduzindo a cultura e o riso

REISS, K. Type, kind and individuality of text: decision making in translation. In: VENUTI, L. (org.). The translation studies reader. London and New York: Routledge, 2000: 160-171.

SUKHIKH, I. Serguei Dovlátov: vriémia, miésto, sudbá. São Petersburgo: NéstorIstória, 2006.

VANDAELE, J. Humor in translation. In: Handbook of Translation Studies. Vol 1. Amsterdam \& Philadelphia: John Benjamins, 2010: 147-52.

Young, J. Sergei Dovlatov and his narrative masks. Evanston, Illinois: Northwestern University Press, 2009.

ZABALBESKOA, P. Humor and translation - an interdiscipline. In: Humor, № 18 - 2. Berlin: Walter de Gruyter, 2005, pp. 185-207.

ZAGUIDÚLLINA, M. Púchkinski mif v kontsé XX vieka. Tcheliábinsk: Izdátelstvo Tcheliábinskovo Gossudárstvennovo Universiteta, 2001. 